\title{
A Case of Invasion of Muscularis Propria of Gastric Inflammatory Fibroid Polyp
}

\author{
Ji Hyeon Lee, Jin Sae Yoo, Ho Yeon Jung, Hee Man Kim, Hun Ryu' ${ }^{1}$ Mee Yon Cho², Hyun Soo Kim \\ Departments of Internal Medicine, General Surgery ${ }^{1}$, and Pathology ${ }^{2}$, Yonsei University Wonju College of Medicine, Wonju, Korea
}

\begin{abstract}
Inflammatory fibroid polyp (IFP) is an uncommon benign tumor and a proliferative disease localized to the submucosal area of the gastrointestinal tract. IFP has been detected more frequently with the increasing use of endoscopy. Histologically, gastric IFP is mostly limited to the submucosa, rarely invading the muscle layer. However, we experienced a case of gastric IFP invading the proper muscle layer. A 62-year-old man was referred for evaluation of epigastric pain. Contrast enhanced computed tomography of the abdomen and endoscopic examination revealed a stomach mass. IFP was histologically confirmed by surgical resection, and the patient was discharged without complication. IFP originating in the stomach that invades the muscularis propria is rare compared to that originating in the large or small intestine. The incidence of gastric IFP is relatively low. Invasion of the muscularis propria by IFP depends not only on the location but also the size of the IFP. There have been no published reports on the outcomes of gastric IFP invading the muscularis propria, therefore close follow-up of the present patient is important. (Korean J Helicobacter Up Gastrointest Res 2015;15:254-257)
\end{abstract}

Key Words: Inflammatory fibroid polyp; Stomach

\section{INTRODUCTION}

Inflammatory fibroid polyp (IFP) is a rare benign tumor and a proliferation disease localized in the submucosal area of the gastrointestinal tract. The clinical presentation of IFP mostly depends on its size and location. IFP usually presents with abdominal pain, weight loss, bleeding, dyspeptic symptoms, and intestinal obstruction or intussusception. Recently, IFP has been diagnosised more frequently with the increasing use of endoscopy. Histologically, gastric IFP is mostly limited to the submucosa, rarely invading the muscle layer. However, we report a case of gastric IFP invading the proper muscle layer, along with a literature review.

\section{CASE REPORT}

A 62-year-old man presented with a 3-month history of epigastric pain and dyspepsia. He had no history of

Received: July 19, 2015 Accepted: October 25, 2015

Corresponding author: Hyun Soo Kim

Department of Internal Medicine, Yonsei University Wonju College of Medicine, 20 Ilsan-ro, Wonju 26426, Korea

Tel: +82-33-741-0114, Fax: +82-33-742-3245, E-mail: hyskim@yonsei.ac.kr medication use, surgery, smoking or alcohol consumption. His physical examination revealed a palpable epigastric mass without tenderness and pale conjunctiva. His nutrition was adequate, and he was in chronic distress, with stable vital signs. On admission, his blood laboratory test results were within the reference ranges, except for a hemoglobin level of $7.5 \mathrm{mg} / \mathrm{dL}$.

Esophagogastroduodenoscopy revealed a $5 \times 5 \mathrm{~cm}$ polypoid mass originating from the posterior wall of the mid antrum (Fig. 1). The mass had caused partial functional obstruction of the gastric outlet. Although the patient had fasted for an adequate amount of time, a significant amount of food was found in his stomach. EUS revealed that the mass originated from the submucosal area (Fig. 1). An initial biopsy of a tissue sample from the mass was performed under endoscopy. The result indicated necrotic inflammatory exudate with granulation tissue formation and spindle cell proliferation. A CT scan of the stomach revealed the origin of the submucosal mass in the stomach (Fig. 2). Thus, we initially suspected a gastrointestinal stromal tumor (GIST). Because GIST is the most common tumor originating from the submucosal area of the stomach, it requires a special immunohistochemical stain. Our patient had to undergo surgical resection of the tumor to

Copyright $\odot 2015$ Korean College of Helicobacter and Upper Gastrointestinal Research

@ The Korean Journal of Helicobacter and Upper Gastrointestinal Research is an Open-Access Journal. All articles are distributed under the terms of the Creative Commons Attribution Non-Commercial License (http://creativecommons.org/licenses/by-nc/4.0) which permits unrestricted non-commercial use, distribution, and reproduction in any medium, provided the original work is properly cited. 

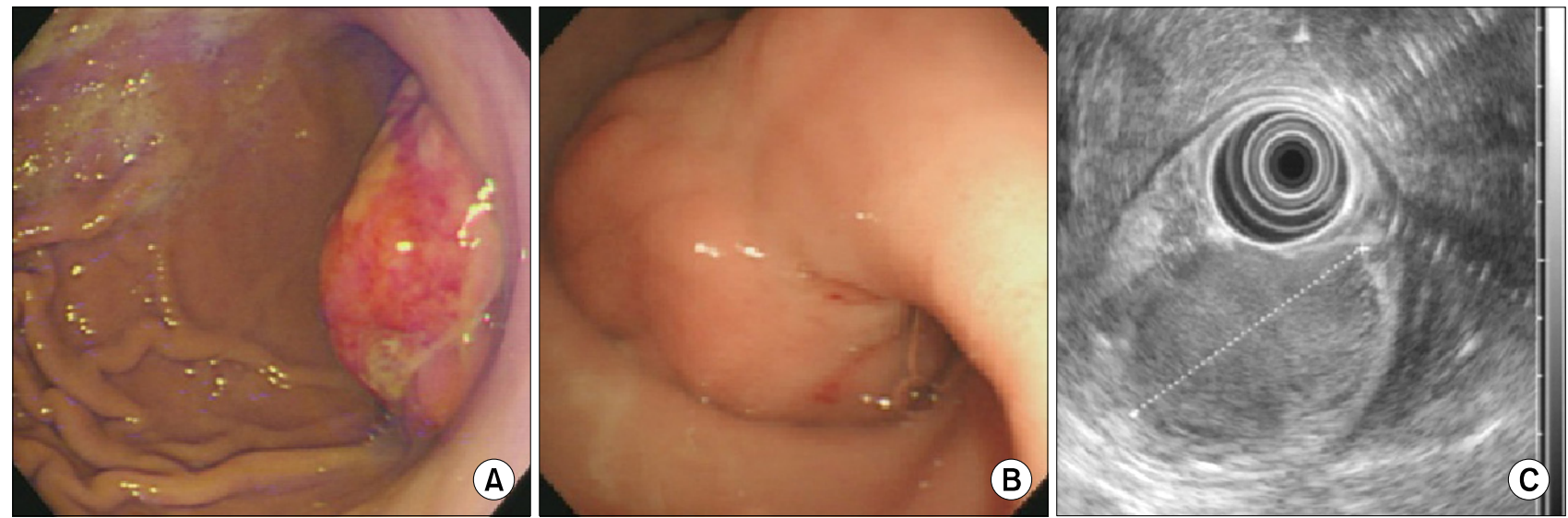

Fig. 1. Endoscopic findings. (A) Endoscopy shows huge gastric polypoid mass and food material. (B) The mass with its stalk arising from the posterior wall of the mid antrum. (C) EUS shows hypoechoic, heterogenous and exophytic mass located in the submucosal layer.
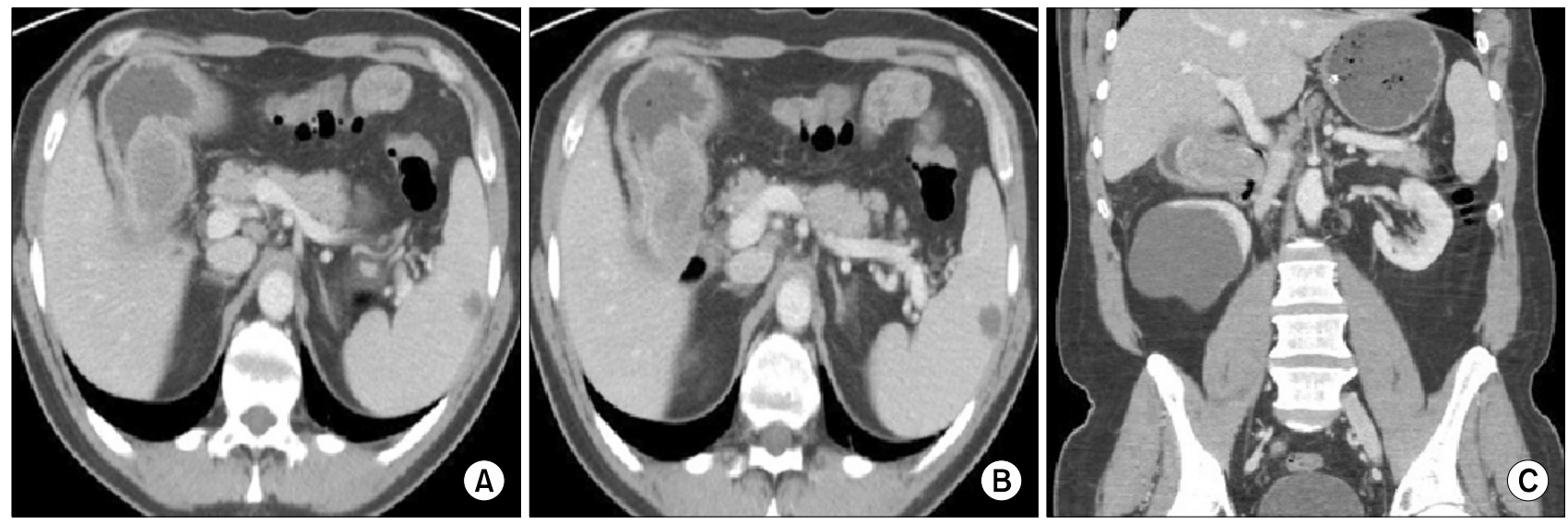

Fig. 2. CT findings. It shows the gastric origin of the submucosal mass, which led to stomach antrum herniation with necrosis (homogeneous enhancement). (A, B) Axial view. (C) Coronal view.

alleviate his symptoms and confirm the malignant potential. We performed laparoscopic resection of the stomach, and the frozen section of the excised tumor revealed a $5 \times 4 \times 2 \mathrm{~cm}$ polypoid mass invading the proper muscle layer (Fig. 3). Histomorphological examination using immunohistochemical stains revealed proliferation of spindle cells and blood vessels, with infiltration of numerous inflammatory cells (Fig. 3), suggestive of IFP, which were all negative for CD34 and smooth muscle actin (expressed in the smooth muscle of blood vessels), CD-117 (c-kit), S-100 protein, and DOG-1. According to these findings, GIST was excluded, and IFP was diagnosed.

After surgical resection, the patient's clinical course was good. He had no complications, and was discharged.

\section{DISCUSSION}

IFP was first described in 1949 by Vanek $^{1}$ as a gastric submucosal granuloma with eosinophilic infiltration., ${ }^{1,2}$ It has also been referred to as a Vanek tumor. ${ }^{3}$ The term "inflammatory fibroid polyp" was first used by Helwig and Ranier ${ }^{4}$ in $19533^{1,4}$ It is composed of blood vessels, fibrotic tissue, and inflammatory infiltration dominated by eosinophils. ${ }^{2,5}$ Immunohistochemical evaluations are often CD34 positive but CD117 negative. ${ }^{6,7}$

The etiology of IFP is unclear, but it is characterized by an inflammatory reaction due to recurrent topical damage of tissue by bacterial, chemical, or metabolic stimulations. ${ }^{4,8-11}$ It usually occurs alone, in adults, ${ }^{4}$ and through- 

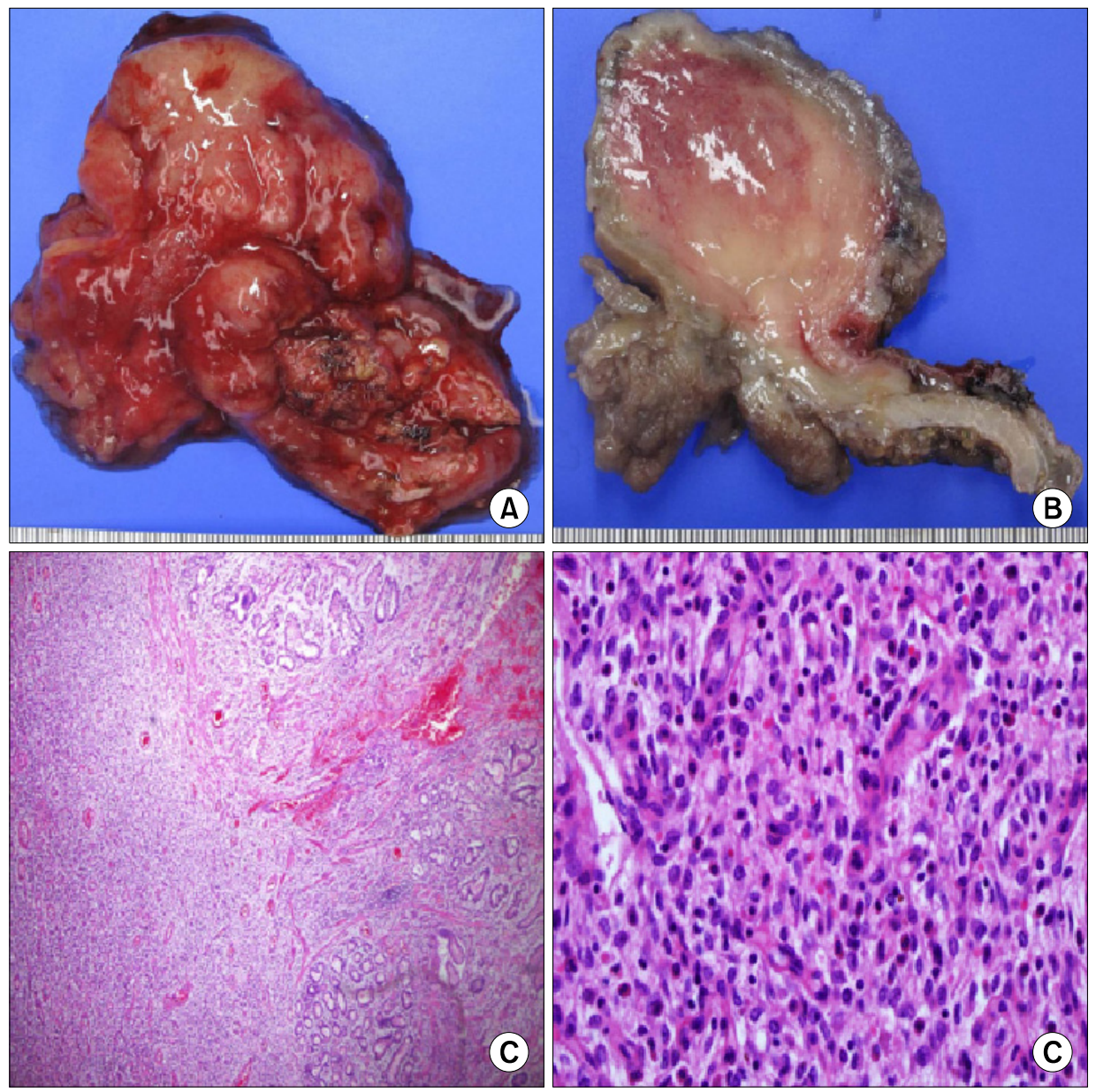

Fig. 3. Pathology. (A) A large $(5 \times 4 \times 2$ $\mathrm{cm})$ polypoid mass with a stalk. (B) Cross-sections of the tumor showing a polyp-like lesion. (C) Histopathological examination shows numerous blood vessels and stroma that are infiltrated with lymphocytes and eosinophils with muscularis propria invasion $(\mathrm{H} \& \mathrm{E}, \times 40)$. (D) It shows spindle cells with infiltration of numerous inflammatory cells $(\mathrm{H} \& \mathrm{E}$, $\times 400)$.

out the gastrointestinal tract. The stomach is the most common site of occurrence. IFP occurs less frequently in the small intestine, large intestine, esophagus, and duodenum. ${ }^{12,13}$

The clinical presentation of IFP depends on its size and location. In the stomach, it commonly causes abdominal pain, as well as bleeding and anemia in rare cases. It is currently common to detect most small asymtomatic IFP by endoscopic examination. ${ }^{9,10,14}$ In contrast, IFP in the small and large intestines are usually large and generate an ileus and bleeding. ${ }^{14}$

IFP is primarily develop in the submucosa, with proliferation of spindle-shaped fibroblasts, fibrous connective tissue, capillary and inflammatory cells are characterized by eosinophil infiltration. ${ }^{1,4,8}$ Mesenchymal spindle cell proliferation sometimes has a perivascular onion-skin-like appearance. It is commonly found in the stomach, with a small tumor size. A large tumor with this feature is rarely observed in the small intestine. ${ }^{3}$ The immunohistochemical staining results for IFP were positive for CD34 and negative for smooth muscle actin, CD117, and S-100. Immunohistochemical staining provides the bases for differential diagnosis of other submucosal fibrotic tissue proliferation diseases, GIST, leiomyoma, and schwannomas. ${ }^{15}$ Staining results are rarely negative for CD34 (primitive mesenchymal cell originated). We believe that IFP can progress, grow in size, and be negative for CD34 and onion skin-like appearance. ${ }^{3}$

The specific reasons for the limitation of gastric IFP to the submucosa and onion-shaped concentric fibrosis around blood vessels remain unknown. In the small intestine, perivascular fibrosis is not visible, while proper muscle invasion is common. ${ }^{2,8,16,17}$

Although gastric IFP rarely invades the muscularis propria, we could not find any detailed case reports of gastric IFP invading the muscularis propria. IFP is a be- 
nign tumor with almost no occurrence of relapse or malignant changes. However, relapse after an endoscopic resection has been reported overseas. ${ }^{18}$ In the case of relapse reported overseas, there was no invasion of the muscularis propria. Regarding IFP in the small and large intestines, invasion of the muscularis propria often occurs. Because of the various symptoms, full surgical resection is performed. When IFP occurs with such symptoms in the stomach, surgical resection is also performed. However, the recent development of endoscopic procedural skills has led to frequent endoscopic resections for a small gastric IFP.

As in the case, radiology examinations such as CT image and EUS image may show that gastric IFP hasn't invaded the muscularis propria. However, it may have invaded the pathologically muscularis propria. For such cases, reports regarding the prognosis in terms of relapse or malignant alteration are lacking. Thus, endoscopic resection should be performed with extra-caution. So we reported the details of the present case to assist with related cases.

\section{REFERENCES}

1. Vanek J. Gastric submucosal granuloma with eosinophilic infiltration. Am J Pathol 1949;25:397-411.

2. Kim YI, Kim WH. Inflammatory fibroid polyps of gastrointestinal tract. Evolution of histologic patterns. Am J Clin Pathol 1988;89:721-727.

3. Daum O, Hes O, Vanecek T, et al. Vanek's tumor (inflammatory fibroid polyp). Report of 18 cases and comparison with three cases of original Vanek's series. Ann Diagn Pathol 2003;7: 337-347.

4. Helwig EB, Ranier A. Inflammatory fibroid polyps of the stomach. Surg Gynecol Obstet 1953;96:335-367.
5. Paikos D, Moschos J, Tzilves D, et al. Inflammatory fibroid polyp or Vanek's tumour. Dig Surg 2007;24:231-233.

6. Trillo AA, Rowden G. The histogenesis of inflammatory fibroid polyps of the gastrointestinal tract. Histopathology 1991;19: 431-436.

7. Hasegawa T, Yang P, Kagawa N, Hirose T, Sano T. CD34 expression by inflammatory fibroid polyps of the stomach. Mod Pathol 1997;10:451-456.

8. Cho NH, Jeong HJ, Kim HG. A pathological and immunohistochemical study of 9 cases of inflammatory fibroid polyp. Korean J Pathol 1989;23:20-28.

9. Tada S, Iida M, Yao T, et al. Endoscopic removal of inflammatory fibroid polyps of the stomach. Am J Gastroenterol 1991;86: 1247-1250.

10. Song DH, Moon JH, Park CW, et al. 4 cases of inflammatory fibroid polyp of the stomach: the findings of endoscopic ultrasonography. Korean J Gastrointest Endosc 1993;13:353362.

11. Kim KH, Seo HJ, Kim JI, et al. Inflammatory fibroid polyp of the stomach mimicking gastric cancer. J Korean Surg Soc 2003; 65:72-75.

12. Bosch O, González Campos C, Jurado A, et al. Esophageal inflammatory fibroid polyp. Endoscopic and radiologic features. Dig Dis Sci 1994;39:2561-2566.

13. Johnstone JM, Morson BC. Inflammatory fibroid polyp of the gastrointestinal tract. Histopathology 1978;2:349-361.

14. Yasuda K, Nakajima M, Kawai K. Endoscopic ultrasonography in the diagnosis of submucosal tumor of the upper digestive tract. Scand J Gastroenterol Suppl 1986;123:59-67.

15. Makhlouf HR, Sobin LH. Inflammatory myofibroblastic tumors (inflammatory pseudotumors) of the gastrointestinal tract: how closely are they related to inflammatory fibroid polyps? Hum Pathol 2002;33:307-315.

16. Shimer GR, Helwig EB. Inflammatory fibroid polyps of the intestine. Am J Clin Pathol 1984;81:708-714.

17. Hwang MK, Kim JH, Park SW, et al. A case of inflammatory fibroid polyp presenting with jejunal bleeding. Korean J Gastroenterol 2003;42:337-340.

18. Zinkiewicz K, Zgodzinski W, Dabrowski A, Szumilo J, Cwik G, Wallner G. Recurrent inflammatory fibroid polyp of cardia: a case report. World J Gastroenterol 2004;10:767-768. 